\title{
THE FIFTH INTERNATIONAL CONGRESS OF MATHEMATICIANS, CAMBRIDGE, 1912.
}

THE local committee of organization was composed of Sir G. H. Darwin, president, E. W. Hobson and A. E. H. Love, secretaries, and Sir J. Larmor, treasurer. Early in the spring circulars were sent out, containing an outline of the proposed plan of procedure and an invitation to participate in the deliberations of the Congress. The date was fixed at August 21 for the opening reception, and meetings were arranged to occupy a week. Members desiring it were permitted to room in the various Colleges, Newnham College being reserved for ladies. Those who took advantage of this provision found their rooms in readiness upon their arrival in Cambridge. The secretaries also compiled a list of boarding and rooming houses in the city, together with a plan indicating the positions of the Colleges and various meeting rooms, so that all the participants were well accommodated.

The elaborate programme of entertainments and excursions which had been prepared for the Congress deserves special consideration. It consisted of four large receptions, an organ recital, and many teas, besides excursions to Ely, Oxford, Hatfield House, and many other interesting places.

The first occasion was a reception given by Sir G. H. Darwin, to meet the Vice-Chancellor, on Wednesday evening in the Combination Room and Hall of St. John's College. This was an ideal place for an introduction to the charming hospitality of Cambridge University.

On Friday evening the Chancellor and Lady Rayleigh gave a reception in the Fitzwilliam Museum. Although each social event was so perfect in its way that comparison is difficult, yet it is not unfair to say that this was the most brilliant affair of the week. The magnificent art galleries, the large number of guests, and the gorgeous academic costumes all contributed to the effect.

The members of the Congress were fortunate in the day chosen by the President to receive them at a garden party. For on Sunday there was the most perfect weather of the week. In the gardens of Christ's College the foreigners received some impression, however faint, of the possibilities of 
an English August. In the evening an organ recital was given in the beautiful chapel of King's College.

The last of the large, formal receptions was held on Monday evening by the Master and Fellows of Trinity College in the Hall and Cloisters.

As regards the excursions, it was necessary to make selections, for they were more numerous than the afternoons. On Monday there were opportunities to visit Ely or the works of the Cambridge Scientific Instrument Company. The latter invitation was extended to Tuesday also. On both afternoons the Hon. Mrs. Horace Darwin served tea after the visit to the works. For Tuesday afternoon there was also an invitation to visit the University Observatory and afterwards to take tea with Professor and Mrs. Newell.

For Wednesday afternoon excursions were planned to Oxford University and Hatfield House. The latter invitation was due to the kindness of the Marquis of Salisbury.

The resourceful committee, who had made such perfect arrangements for everything on the general programme, made provision also for those ladies who had no interest in purely scientific matters. A supplementary programme was arranged, under the direction of a ladies' committee, with Lady Darwin as chairman. There were popular lectures, specially conducted visits to the various colleges, and teas given by ladies of Cambridge and by Sir Charles and Lady Waldstein.

But perhaps the most unique feature of the social arrangements was to be found in the opportunity-so freely and cordially offered to the members of the Congress - to live in these historical old buildings and to share, in a degree, the life of the University. It was characteristic of British hospitality.*

On the afternoon of the last day of the Congress a large number of members proceeded to Cayley's grave and deposited there a wreath in his memory. Funds were contributed for a silver wreath to be presented to the University as a permanent tribute of honor and respect for this great Cambridge mathematician.

At the last session of the Congress it was reported that 706 persons had been registered as in attendance, of whom 573 were active participants, representing 27 different countries.

* The above report of the social side of the Congress was prepared by Dr. Elizabeth B. Cowley, of Vassar College. 
On the motion of Professor Mittag-Leffler it was voted to hold the next Congress in Stockholm in 1916.

Professor A. G. Webster appropriately voiced the heartfelt appreciation and thanks of the members of the Congress for the cordial hospitality lavishly showered upon them, collectively and individually, by their gracious hosts. All present expressed their hearty participation in his tribute by prolonged applause and an enthusiastic rising vote. Thereupon a few fitting words of the chairman, Sir George Darwin, brought the fifth international congress of mathematicians to a close.

The sectional work of the Congress was distributed as follows:

I. Arithmetic, Algebra, Analysis.

II. Geometry.

III a. Mechanics, Physical Mathematics, Astronomy.

III $b$. Economics, Actuarial Science, Statistics.

IVa. Philosophy and History.

IVb. Didactics.

The International commission on the teaching of mathematics held one separate session and three sessions jointly with Section IVb.

A meeting of the international committee was held at 5 P. M., Wednesday, August 21, to complete the final arrangements.

The opening meeting of the Congress was held at $10 \mathrm{~A}$. M. on Thursday. Sir G. H. Darwin, President of the Cambridge Philosophical Society, spoke as follows:

Four years ago at our conference at Rome the Cambridge Philosophical Society did itself the honor of inviting the International Congress of Mathematicians to hold its next meeting at Cambridge. And now I, as president of the society, have the pleasure of making you welcome here. I shall leave it to the vice-chancellor, who will speak after me, to express the feeling of the university as a whole on this occasion, and I shall confine myself to my proper duty as the representative of our scientific society.

The science of mathematics is now so wide and is already so much specialized that it may be doubted whether there exists to-day any man fully competent to understand mathematical research in all its many diverse branches. I, at least, feel how profoundly ill equipped I am to represent our society 
as regards all that vast field of knowledge which we classify as pure mathematics. I must tell you frankly that when I gaze on some of the papers written by men in this room I feel myself much in the same position as if they were written in Sanskrit.

But if there is any place in the world in which so one-sided a president of the body which has the honor to bid you welcome is not wholly out of place it is perhaps Cambridge. It is true that there have been in the past at Cambridge great pure mathematicians such as Cayley and Sylvester, but we surely may claim without undue boasting that our university has played a conspicuous part in the advance of applied mathematics. Newton was a glory to all mankind, yet we Cambridge men are proud that fate ordained that he should have been Lucasian professor here. But as regards the part played by Cambridge I refer rather to the men of the last hundred years, such as Airy, Adams, Maxwell, Stokes, Kelvin, and other lesser lights, who have marked out the lines of research in applied mathematics as studied in this university. Then too there are others such as our chancellor, Lord Rayleigh, who are happily still with us.

Up to a few weeks ago there was one man who alone of all mathematicians might have occupied the place which I hold without misgivings as to his fitness; I mean Henri Poincaré. It was at Rome just four years ago that the first dark shadow fell on us of that illness which has now terminated so fatally. You all remember the dismay which fell on us when the word passed from man to man 'Poincaré is ill.' We had hoped that we might again have heard from his mouth some such luminous address as that which he gave at Rome; but it was not to be, and the loss of France in his death affects the whole world.

It was in 1900 that, as president of the Royal Astronomical Society, I had the privilege of handing to Poincaré the medal of the society, and I then attempted to give an appreciation of his work on the theory of the tides, on figures of equilibrium of rotating fluid, and on the problem of the three bodies. Again in the preface to the third volume of my collected papers I ventured to describe him as my patron saint as regards the papers contained in that volume. It brings vividly home to me how great a man he was when I reflect that to one incompetent to appreciate fully one half of his work he yet appears as a star of the first magnitude. 
It affords an interesting study to attempt to analyze the difference in the textures of the minds of pure and applied mathematicians. I think that I shall not be doing wrong to the reputation of the psychologists of half a century ago when I say that they thought that when they had successfully analyzed the way in which their own minds work they had solved the problem before them. But it was Sir Francis Galton who showed that such a view is erroneous. He pointed out that for many men visual images form the most potent apparatus of thought, but for others this is not the case. Such visual images are often quaint and illogical, being probably often founded on infantile impressions, but they form the wheels of the clockwork of many minds. The pure geometrician must be a man who is endowed with great powers of visualization, and this view is confirmed by my recollection of the difficulty of attaining to clear conceptions of the geometry of space until practice in the art of visualization had enabled one to picture clearly the relationship of lines and surfaces to one another. The pure analyst probably relies far less on visual images, or at least his pictures are not of a geometrical character. I suspect that the mathematician will drift naturally to one branch or another of our science according to the texture of his mind and the nature of the mechanism by which he works.

I wish Galton, who died but recently, could have been here to collect from the great mathematicians now assembled an introspective account of the way in which their minds work. One would like to know whether students of the theory of groups picture to themselves little groups of dots, or are they sheep grazing in a field. Do those who work at the theory of numbers associate color, or good or bad characters, with the lower ordinal numbers and what are the shapes of the curves in which the successive numbers are arranged? What I have just said will appear pure nonsense to some in this room, others will be recalling what they see, and perhaps some will now for the first time be conscious of their own visual images.

The minds of pure and applied mathematicians probably also tend to differ from one another in the sense of esthetic beauty. Poincaré has well remarked in his Science et Méthode (page 57):

'On peut s'étonner de voir invoquer la sensibilité à propos de démonstrations mathématiques qui, semble-t-il, ne peuvent 
intéresser que l'intelligence. Ce serait oublier le sentiment de la beauté mathématique, de l'harmonie des nombres et des formes, de l'élegance géometrique. C'est un vrai sentiment esthétique que tous les vrais mathématiciens connaissent. Et c'est bien là de la sensibilité.'

And again he writes:

'Les combinaisons utiles, ce sont précisément les plus belles, je veux dire celles qui peuvent le mieux charmer cette sensibilité spéciale que tous les mathématiciens connaissent, mais que les profanes ignorent au point qu'ils sont souvent tentés d'en sourire.'

Of course there is every gradation from one class of mind to the other, and in some the esthetic sense is dominant and in others subordinate.

In this connection I would remark on the extraordinary psychological interest of Poincaré's account, in the chapter from which I have already quoted, of the manner in which he proceeded in attacking a mathematical problem. He describes the unconscious working of the mind, so that his conclusions appeared to his conscious self as revelations from another world. I suspect that we have all been aware of something of the same sort, and like Poincaré have also found that the revelations were not always to be trusted.

Both the pure and applied mathematicians are in search of truth, but the former seeks truth in itself and the latter truths about the universe in which we live. To some men abstract truth has the greater charm, to others the interest in our universe is dominant. In both fields there is room for indefinite advance, but while in pure mathematics every new discovery is a gain, in applied mathematics it is not always easy to find the direction in which progress can be made, because the selection of the conditions essential to the problem presents a preliminary task, and afterwards there arise the purely mathematical difficulties. Thus it appears to me at least, that it is easier to find a field for advantageous research in pure than in applied mathematics. Of course if we regard an investigation in applied mathematics as an exercise in analysis the correct selection of the essential conditions is immaterial, but if the choice has been wrong the results lose almost all their interest. I may illustrate what I mean by reference to Lord Kelvin's celebrated investigation as to the cooling of the earth. $\mathrm{He}$ was not and could not be aware of the radio-activity of the 
materials of which the earth is formed, and I think it is now generally acknowledged that the conclusions which he deduced as to the age of the earth cannot be maintained; yet the mathematical investigation remains intact.

The appropriate formulation of the problem to be solved is one of the greatest difficulties which beset the applied mathematician, and when he has attained to a true insight but too often there remains the fact that his problem is beyond the reach of mathematical solution. To the layman the problem of the three bodies seems so simple that he is surprised to learn that it cannot be solved completely, and yet we know what prodigies of mathematical skill have been bestowed on it. My own work on the subject cannot be said to involve any such skill at all, unless indeed you describe as skill the procedure of a housebreaker who blows in a safe-door with dynamite instead of picking the lock. It is thus by brute force that this tantalizing problem has been compelled to give up some few of its secrets, and great as has been the labor involved I think it has been worth while. Perhaps this work too has done something to encourage others, such as Störmer, to similar tasks as in the computation of the orbits of electrons in the neighborhood of the earth, thus affording an explanation of some of the phenomena of the aurora borealis. To put at their lowest the claims of this clumsy method, which may almost excite the derision of the pure mathematician, it has served to throw light on the celebrated generalizations of Hill and Poincaré.

I appeal then for mercy to the applied mathematician and would ask you to consider in a kindly spirit the difficulties under which he labors. If our methods are often wanting in elegance and do but little to satisfy that esthetic sense of which I spoke before, yet they are honest attempts to unravel the secrets of the universe in which we live.

We are met here to consider mathematical science in all its branches. Specialization has become a necessity of modern work and the intercourse which will take place between us in the course of this week will serve to promote some measure of comprehension of the work which is being carried on in other fields than our own. The papers and lectures which you will hear will serve towards this end, but perhaps the personal conversations outside the regular meetings may prove even more useful. 
Mr. R. F. Scott, Vice-Chancellor of the University of Cambridge, spoke as follows:

Gentlemen: It is my privilege to-day on behalf of the University of Cambridge and its Colleges to offer to members of the Congress a hearty welcome from the resident body.

Sir George Darwin has dwelt on the more serious aspects of the meeting and work of the Congress; may I express the hope that it will also have its lighter and more personal side? That we shall all have the privilege and pleasure of making the personal acquaintance of many well known to us both by name and by fame, and that those of our visitors who are not familiar with the college life of Oxford and Cambridge will learn something of a feature so distinctive of the two ancient English universities. If the Congress comes at a time when it is not possible to see the great body of our students either at work or at play, the choice of date at least renders it possible that many of our visitors may enjoy for a time that collegiate life which has so many attractions.

I see that one of the Sections of the Congress deals with historical and didactical questions. Those members of the Congress who are interested in these subjects will have an opportunity of learning on the spot something of our methods in Cambridge, and of the history of our chief mathematical examination, the mathematical tripos, and of its influence on the study and progress of mathematics both in Cambridge and Great Britain.

The researches of Dr. Venn seem to point to the fact that until it was altered at a very recent date the mathematical tripos represented something like the oldest example in Europe of a competitive examination with an order of merit. Those who are interested in such matters of history will find much to interest them in Mr. Rouse Ball's History of the Study of Mathematics at Cambridge.

The subject is to me, and I hope to others, an interesting one. There can be no doubt that the examination and the preparation for it has had a profound influence on mathematical studies at Cambridge.

Many Cambridge mathematicians, as the names given by Sir George Darwin testify, studied mathematics for its own sake and with the view of extending the boundaries of knowledge. Many others, probably the great majority, studied mathematics with their eyes fixed upon the mathematical 
tripos, with the view in the first place of being examined and afterwards of acting as examiner in it.

The tendency at Cambridge has been to give great minuteness to the study of any particular branch of mathematics, to stimulate the invention of what we call "problems," examples of more general theories. If I may borrow a simile from the study of literature the tendency was to produce critics and editors rather than authors or men of letters, followers rather than investigators. The effect must I think be obvious to any one who compares Cambridge text books and treatises with those of the continental schools of mathematics. I may illustrate what I mean by referring to the Mathematical Problems of the late Mr. Joseph Wolstenholme, a form of work I believe without a parallel in the mathematical literature of other nations. The fashion is fading away, but while you are in Cambridge I commend it to your notice.

Professor E. W. Hobson, senior secretary of the Organizing Committee, stated that the number of persons who had joined the Congress up to 10 P. M. on Wednesday, August 21, was 670 , the number of representatives of different countries being as follows: Austria 19, Belgium 4, Brazil 4, Bulgaria 1, Canada 4, Chili 1, Denmark 5, Egypt 2, France 52, Germany 70, Great Britain 250, Greece 5, Holland 9, Hungary 19, India 3, Italy 38, Japan 3, Mexico 1, Norway 4, Portugal 3, Roumania 5, Russia 38, Servia 1, Spain 25, Sweden 13, Switzerland 9, United States 82. He also called the attention of the members of the Congress to the exhibition of books, models and machines (chiefly calculating machines) arranged in two rooms of the Cavendish Laboratory.

The first general meeting of the Congress was held at 2.30 P. M.

On the motion of Professor Mittag-Leffler, seconded by Professor Enriques, Sir G. H. Darwin was elected president of the Congress.

On the motion of the president it was agreed that Lord Rayleigh be made honorary president of the Congress.

\section{General Lectures.}

Eight general lectures were provided for the afternoons as follows: 
1. Enriques, F., Bologna: "Il significato della critica dei principii nello sviluppo delle matematiche."

2. Brown, E. W., New Haven: "Periodicity in the solar system."

3. Landau, E., Göttingen: “Gelöste und ungelöste Probleme aus der Theorie der Primzahlverteilung und der Riemann'schen Zetafunktion."

4. Galitzin, B., St. Petersburg: "The principles of instrumental seismology."

5. Borel, E., Paris: "Définition et domaine d'existence des fonctions monogènes uniformes."

6. White, W. H., London: "The place of mathematics in engineering practice."

7. Bôcher, M., Cambridge, Mass.: "Boundary problems in one dimension."

8. Larmor, J., Cambridge, Eng.: "The dynamics of radiation."

Abstracts of the lectures follow below.

\section{Professor F. Enriques.}

An analysis of fundamental principles is the order of the day among contemporary mathematicians. The profound analysis of the concepts of limit and of function, the investigations having for point of departure the theory of parallels and of non-euclidean geometry, the more recent ones concerning the foundations of geometry and of analysis situs, the developments on varieties of several dimensions, on transformations and their groups, these and other problems have given rise to a series of questions lying at the very roots of the mathematical edifice, and of philosophic thought.

History furnishes instructive information on this point. The analysis of principles is not, properly speaking, a new phenomenon, characterizing our time; it is, on the contrary, an essential part of the elaboration of the concepts which in every age accompanies the progress of the science and of its application. The universally admired perfection of the work of Euclid is revealed to the historian as the natural product of a long criticism which was developed in the constructive period of rational geometry, from Pythagoras to Eudoxus. Then commenced to appear the signification of those methods and principles by means of which the Greeks themselves attempted 
to interpret and to conquer the paradoxes concerning infinity. These are the same difficulties which reappeared at the time the infinitesimal calculus was founded, and are now again asserting themselves in the most refined analysis.

The foundation of mensuration first raised the question of geometric continuity, and the relation between the side and the diagonal of a square presented an insurmountable difficulty to the Pythagorean school. The contributions of Eudoxus and of Archimedes not only showed this question in its true light, but also contained the correct elements of the calculus.

The second period was ushered in by Galileo, Fermat, Descartes, Wallis, Roberval, etc., and was soon followed by the epoch-making advances of Newton and of Leibniz in the concept of an analytic limit and of the derivative.

The foundations of their methods and the correctness of their results were soon to be justified and clarified by the researches of Lagrange and of Carnot. These same ideas have again been considered by Cauchy, Riemann, Weierstrass, and have served as basis of the theory of the calculus of variations which has received so much attention during the last few years.

Another line of development is marked by the concept of an arbitrary function and the modern elaboration of the concept of infinity, inaugurated by Dirichlet and by Abel and Jacobi, respectively, later to be refined by Riemann, Weierstrass, Dini, Cantor, Dedekind, Veronese, Poincaré and Hilbert. Throughout all this growth, the fundamental idea of geometric continuity, as understood today, is still that of Eudoxus and of Archimedes.

Corresponding to the growth of the concepts already mentioned, another point of view was being presented, which may be called intensive mathematics, the establishing of the line of demarcation between intuition and of logical proof. The study of irrational numbers and of algebraic equations together with their natural extension to that of differential equations, to integral equations, and their various combinations, lead to a properly intense study of the principles of mathematics. These studies have found their present culmination in the theory of algebraic functions, the foundations of geometry and in certain developments of algebra, illustrated by the Clebsch-Noether theory and by recent investigations of Picard and of Poincaré. 
The criticism of principles forms an integral part of the history of the development of mathematics, as well from the extensive as from the intensive point of view.

Even the exaggerations to which modern criticism may lead have served to convey a correct idea of the value of logic by contrast, by comparing with the results obtained by other processes. The importance of the concept of logic thus brought to light has given rise to the philosophy called pragmatism.

Those who oppose this concept of our physical experiences idealized wish to see in mathematics only an instrument to be used in natural sciences. But such a view (which the exaggerations of logical pragmatism could, by reaction, suggest to certain minds) would have the effect of singularly restricting the field of mathematics.

\section{Professor E. W. Brown.}

After pointing out the different branches into which celestial mechanics has become divided during the last thirty years, the lecturer dwelt at some length on the periods of the oscillations by which astronomers have usually expressed the motions of the bodies of the solar system. These oscillations are of short-period, long-period, secular, and librational. It was then shown how, by a consideration of these periods, we can make certain that the present theories of the moon and planets shall fully represent the motions of those bodies during the limited time for which observations exist.

The theories for the asteroids are much more difficult. In them, approximate or exact commensurability between the mean period of revolution of the asteroid round the sun and that of Jupiter plays an important part. Exact commensurability, if it exists, produces oscillations which are generally known as librations, and the mathematical theory of these is still in a very incomplete state. So far as we know, there is no reason why librating asteroids should not exist. But there are notable deficiencies in the libration regions. A similar state of things occurs in the ring of Saturn. On the other hand, we have librations in the satellite systems of both Jupiter and Saturn. It was suggested that the presence of a libration region in the problem of three bodies limits the range of stable orbits and that a still greater limitation of the range is produced by the presence of a fourth body, e. g., of Saturn, when the asteroids are under consideration. 
The periodic deviations of the moon from its theoretical orbit were briefly dealt with and methods for exploring their sources were mentioned. Professor Brown concluded his lecture with a warm tribute of respect to the memory of Henri Poincaré.

\section{Professor E. Landau.}

Familiarity with the theory of numbers is by no means general among mathematicians; in particular, the difficulties of the analytic theory of numbers have not been attractive, so that but few are familiar with the elegant results of the theory.

After stating the problem of the lecture, a rapid resumé of preceding results and methods was given, and a concise statement of several new results, particularly those of Littlewood, Bohr, and Landau, was added.

Four definite questions were put, the solutions of which were considered as impossible in the present state of the science.

1. Does the function $u^{2}+1, u$ an integer, represent an infinite number of primes?

2. Does the equation $m=p+p^{\prime}$ have a solution in prime numbers for every even value of $m$ ?

3 . Has the equation $2=p-p^{\prime}$ an infinite number of prime solutions?

4. Does at least one prime number lie between $n^{2}$ and $(n+1)^{2}$ for every integral value of $n$ ?

\section{Prince B. Galitzin.}

The rapid advance of seismology in the last twenty years is mainly due to the fact that this new scientific discipline has adopted pure physical methods of research based upon instrumental observations. Instrumental seismology or seismometry, in devising its instruments of research, stands in close connection with theoretical mechanics, so intimately linked with pure mathematics. The propagation of seismic disturbances, generated in the focus of an earthquake, is nothing but a problem in the theory of elasticity. According to the latter two types of seismic waves are propagated through the interior of the earth, viz., longitudinal and horizontal or transverse waves, the velocities of which in the upper strata of the earth's crust are respectively equal to 7.17 and 4.01 
kilometers per second. From the difference of time of arrival of these characteristic disturbances at a given point, the epicentral distance can be deduced.

The general equations of the theory of elasticity lead, as Lord Rayleigh and Lamb have shown, to the conclusion that another class of waves, viz., gravitational or long waves, are propagated with a constant velocity 3.5 along the surface of the earth. The arrival of these waves constitutes the beginning of the maximal phase of a seismogram. These theoretical results are confirmed in their general outlines by direct observations.

Instead of studying the seismic waves in the interior of the earth, it is more convenient to consider the corresponding seismic rays, which travel along characteristic paths. If the law which gives the relationship between velocity and depth were known, one could easily express the time of traveling from the focus to the point of observation as well as the corresponding epicentral distance as function of the depth of the focus and the angle of emergence of the seismic rays. This would give the form of the so-called vertical hodograph curve. By recording the problem, that is, plotting the form of the hodograph from direct observations, it is possible to get at some conclusions concerning the interior construction of the earth. This is the procedure adopted by Wiechert and his students.

Whereas in the boundaries of the epicentral area nearly every earthquake is characterized by several more or less intensive shocks, separated by intervals of calm, the whole disturbance seldom lasting more than a few minutes, seismic records at distant stations reveal a continuous and very prolonged motion of the ground. This stretching out of seismograms at distant stations may be attributed to inner reflections and refractions of the rays, to the release of normal vibrations of the earth's outer shell and to seimic dispersion. The problem of seismic dispersion has not been thoroughly investigated.

The proper way to treat the different problems of the propagation of seismic waves would be to consider the different layers of the earth not as an isotropic, but only as a transversely isotropic medium. This is the method followed by Rutzki, which has led him to obtain very interesting results, but the problem is a very difficult one.

Instrumental observations, which form the basis of modern 
seismology, are always capable of giving, after a careful analysis of the record, the true movement of the element of the earth's surface. As there are six different possible displacements, three translations and three rotations, the problem of solving the fundamental problem of seismology, which is to find the true motion of the ground as function of the time, requires six different seismographs. The rotation about a horizontal axis corresponds to a tilting of the ground. For distant earthquakes this tilting is so small that translations alone are studied at present. To study the true movement of a particle of the earth's surface, different types of seismographs are used, all of which are based upon the principle of inertia, that is, upon the principle of the so-called steady point.

As it is necessary, in order to obtain a high magnification, that the proper period of oscillation of the seismograph should be long, horizontal pendulums are most frequently used for the study of horizontal displacements. There are different types of horizontal pendulums, those with two pivots (RebewDaschwitz), those with one pivot or flat spring (Molne, OmsriBosch, Mainka, Galitzin), or with no pivots at all and where the heavy mass is supported by two inclined wires (Zöllner, suspension). These latter pendulums introduce no friction and are of a very sensitive nature. They are used at all Russian first class seismic observatories. Wiechert's improved astatic pendulum is also much used.

To study the vertical component special vertical seismographs are used, based upon the use of springs (Vicatiori, Wiechert, Galitzin).

The movements of the seismograph needle are registered either mechanically by means of smoked paper or optically by means of a reflected ray of light. The former method introduces a good deal of friction, especially when magnifying levers are used, and are in effect troublesome. To avoid a very high magnification and avoid all friction, galvanometric registration is very advantageous. It consists in fixing to the pendulum boom several induction coils between the poles of a pair of horse-shoe magnets. When the boom is set in motion electric currents are generated in the coils and are transmitted to a very sensitive dead-beat galvanometer, whose movements are directly recorded optically. This method of registration offers many advantages, the principal one of which is that it admits of registration at a distance. 
In order to obtain trustworthy records, from which one may deduce the true motion of the ground, every seismograph ought to be highly damped. This is at present a well-known and adopted axiom, but it has not as yet found its practical realization in all countries. At present air and oil damping are used, but the most simple, practical and theoretically sound mode of damping is that of magnetic damping, which is being introduced at all Russian seismic observatories.

The fundamental problem of seismology, that is, the determination of the true motion of the ground for a given interval of time, offers great difficulties, where the aid of mathematicians, as in many other fields of modern science, is much needed.

The reading of seismograms obtained by galvanometric registration from aperiodic seismographs enables us to attack different problems, some of which are of great practical importance for modern seismology.

From the readings of the aperiodic horizontal pendulums at right angles to each other at the beginning of the first phase, when the first longitudinal waves strike the ground, one can deduce the true azimuth of the epicentral; by combining this result with the epicentral distance, deduced from the difference of time of arrival of the first horizontal and longitudinal waves, we can locate the position of an epicenter from observations made at one station only. This is the method exclusively used at present at the seismic observatory at Pulkava. Taking into consideration also the displacement of the vertical seismograph we can obtain the visible angle of emergence of the seismic rays, which is a very important element for the study of the paths of the seismic rays in the interior of the earth.

The instruments devised up to the present to study the tilting of the ground independently of all displacements have not led to practical results, but a double differential pendulum with galvanometric registration seems to be a well adapted instrument for that purpose, as experiments made with a variable platform have shown that it is entirely uninfluenced by any displacements at all, however irregular they may be.

The study of extraseismic movements in the epicentral area itself may be based upon observations of excited blocks. 


\section{Professor E. Borel.}

Cauchy insisted on various occasions on the importance of monogeneity. If we consider an elementary function obtained by simple operations on $z$ (polynomials in $z$, series in $z$ everywhere convergent representing the exponential series, trigonometric functions, etc.) and if, for such a function $F(z)$ we calculate the ratio

$$
\frac{F(z+\Delta z)-F(z)}{\Delta z},
$$

then if this ratio tends towards a definite limit, as $\Delta z$ approaches zero, independently of the manner in which $\Delta z$ approaches zero, Cauchy calls the function $F(z)$ monogenic.

It is by aid of the fundamental theorem of Cauchy,

$$
f(\zeta)=\frac{1}{2 \pi i} \int_{c} \frac{f(z) d z}{z-\zeta},
$$

that we demonstrate that homogeneity in a domain $W$ implies analyticity within the domain.

We must also have recourse to this theorem to study functions which are monogenic in a domain other than $W$; it will be convenient, in order to reason in a most general manner concerning the deductions from possible definitions of these functions, to consider them as defined according to Riemann, that is, admitting that we know nothing of such a function, except that it is monogenic. It is also necessary to show that the theory thus constructed is not meaningless, by furnishing actual examples of functions defined in a manner that is not ideal, but explicit.

Functions which are monogenic but not analytic possess the most important properties of analytic functions; in particular, for a region $C$, the existence of the first derivative implies the existence of derivatives of all orders.

The transformation of Cauchy's integral into a double integral corresponds to the hypothesis, physically natural enough, that there are no infinite masses, but only singular regions in which the density can be very high, or, if one prefers, "spheres" of finite action attached to each singular point. Monogenic non-analytic functions correspond to the case in which the singular regions are at once extremely small 
and extremely numerous. I pointed out some time ago that by means of certain arithmetic dispositions of such singular regions, the lines of continuity which touch these regions without penetrating them can be such that their properties are intimately connected with the numerical simplicity of their coefficients of direction. I do not know whether some analyst more skilled than I may some day draw from these somewhat vague considerations consequences of interest to physicists, but it is impossible for me to ignore the fact that I have often been guided by the analogies of the new theory with the theory of molecular physics, to the progress of which this city and this country have so powerfully contributed.

\section{Sir W. H. White.}

The foundations of modern engineering have been laid on mathematics and physical science; the practice of engineering is now governed by scientific methods applied to the analysis of experience and the results of experimental research. Engineering has been defined as " the art of directing the great sources of power in nature for the use and convenience of man." An adequate acquaintance with the laws of nature, and obedience to those laws, are essential to the full utilization of these sources of power. It is now universally recognized that the educated engineer must possess a good knowledge of the sciences which bear upon his professional duties, in combination with thorough practical training and experience in actual engineering work. Neither side of his education can be neglected without hampering him seriously, especially when he has to go beyond precedent and face new problems. Of these sciences, the mathematical is undoubtedly of the greatest importance to engineers. The range and character of mathematical knowledge which can be considered adequate are gradually being agreed upon as experience is enlarged; and present ideas are embodied in the courses of study prescribed in the calendars of schools of engineering. Absolute identity in the courses of study and the standards laid down for degrees in engineering has not been attained, but the approach thereto has already been considerable, and the movement will undoubtedly continue in the same direction.

The preponderance of opinion amongst engineers now favors the teaching to students of engineering of science generally, 
and of mathematics in particular, being undertaken by recognized authorities in the several branches, and on lines which shall ensure greater breadth of view and fuller capability for dealing with new problems arising in their professional work, than can be secured by means of special courses of instruction arranged for students of engineering as a class apart. Whatever branch of engineering a man may select for his individual practice, he must need a fundamental knowledge of mathematics, and in some branches in order to do his work well he will require to add considerably to the mathematical knowledge which is sufficient for a degree. As time passes, the mathematician and the practicing engineer have come to understand one another better, and to be mutually helpful. While engineers as a class cannot claim to have made many important or original contributions to mathematical science, some men trained as engineers have done notable work of a mathematical character. The names of Rankine, William Froude, and John Hopkinson, amongst British engineers, also hold an honored place in mathematics. Mathematicians of eminence have spent their lives in the tuition of engineers, and in that way have greatly influenced the practice of engineering; but while they have necessarily become familiar with the problems of engineering as a consequence of their connection therewith, they have not accomplished much actual engineering work, and none of it has been of first importance. Speaking broadly there is an abiding distinction between mathematicians and engineers. Mathematicians regard engineering chiefly from the scientific point of view, and are primarily concerned with the bearing of mathematics on engineering practice, the construction of theories and the framing of useful rules. Engineers, even when well equipped with mathematical knowledge, are primarily devoted to the design and construction of efficient and durable works; their main object being to secure the best possible association of efficiency and economy, and so to achieve practical and commercial success. There is evidently room for both classes, and their collaboration in modern times has produced wonderful results.

The proper use of mathematics in engineering practice is now generally agreed to include the following steps. First comes the development of a mathematical theory based on assumptions which are thought to embody and to represent 
conditions disclosed by past practice and observation. Frequently these theoretical investigations give rise to valuable suggestions for further observations or experimental investigations. Mathematical analysis must be applied to the results of observation and experiment; and as a result amendments or extensions are made of the original mathematical theory. Useful rules are also devised, in many instances, which serve for guidance in the future practice of engineers. Formerly it was thought by men of science that purely mathematical investigation and reasoning would do all that was required for the guidance of engineering practice; now it is admitted that such investigations will not suffice, and that the chief services which can be rendered to engineering by mathematicians will consist in the suggestion of the best directions and methods for experimental research, the conduct of observations on the behavior of existing works, the establishment of general principles based on analysis of experience, and the framing of practical rules embodying scientific principles.

The contrast between present and past methods can be illustrated by comparing investigations made during the eighteenth century, into the behavior of ships amongst waves by Daniel Bernoulli who won the prize offered by the Royal French Academy of Science in 1757, and work done by William Froude a century later in connection with the same subjects. Bernoulli was the greater mathematician but had only a small knowledge of the sea and of ships. His memoir was a mathematical treatise; his practical rules, although deduced from mathematical investigations which were themselves correct, depended upon certain fundamental assumptions which did not correctly represent either the phenomena of wave motion or the causes producing and limiting the rolling oscillations of ships. Bernoulli realized and dwelt upon the need for further experiment and observation and showed remarkable insight into what was needed, but the fact remains that he neither made such experiments himself nor was able to induce others to make them. As a consequence, his practical rules for the guidance of naval architects were incorrect and would have produced mischievous results if they had been applied in practice. Williäm Froude was a trained engineer who had a good knowledge of mathematics and a mathematical mind. His acquaintance with the sea and ships was considerable; 
his skill as an experimentalist was remarkable, and he was fortunate enough to secure the support of the Admiralty, through the constructive department. He thus obtained the services of the officers of the Royal Navy in making a long series of accurate and detailed observations of the characteristic features of ocean waves as well as the rolling of ships amongst waves or in still water. In this way, starting with the formulation of a mathematical theory of wave motion, and of a theory for unresisted rolling in still water and amongst waves, Froude added corrections based on experimental research and succeeded eventually in devising methods by means of which naval architects can make close approximations to the probable behavior of ships of new design when exposed to the action of waves, either forming a regular series or constituting an irregular sea. In these approximations allowance can be made for the effect of water resistance to the rolling motion-a most important factor in the problem which could not be dealt with until experimental research had been made, and results had been subjected to mathematical analysis. In addition, Froude laid down certain practical rules for the guidance of naval architects, and the application of these rules has been shown by long experience to favor the steadiness-that is to say the comparative freedom from rolling-of ships designed in accordance with these rules. In short a problem which had proved too difficult when attacked by Daniel Bernoulli in purely mathematical fashion was practically solved a century later by Froude, who employed a combination of mathematical treatment and experimental research.

Another example of the contrast between earlier and present methods is to be found in the treatment of the resistance offered by water to the onward motion of ships. From an early date mathematicians have been attracted to this subject, and many attempts were made to frame mathematical theories. When steam propulsion for ships was introduced, the matter became of great practical importance, because it was necessary to make estimates for the engine power required to drive a ship at the desired speed. In making such estimates it was necessary to approximate to the value of the water resistance at that speed, although the required engine power was also influenced by the efficiency of the propelling apparatus and propellers. In addition it was obvious that the water resistance to the motion of a ship when she was driven by her 
propellers at a given speed would be in excess of the resistance experienced if she were towed at the same speed, and there was no exact knowledge in regard to that increment of resistance. The earlier mathematical theories of resistance prove to be of little or no service, and they were based on erroneous and incomplete assumptions. Rankine devised a "stream line" theory which was superior to its predecessors, but it also for a time had no effect on the practice of naval architects. William Froude, adopting this stream line theory, dealt separately with frictional resistance, and devised a "law of comparison" at corresponding speeds by which from the " residual resistance" of models-exclusive of frictionit became possible to estimate the corresponding residual resistance for ships of similar forms. At first he stood alone in advocating these views, but subsequent experience during forty years has demonstrated their soundness. Experimental tanks for testing models of ships, such as Froude introduced, are now established in all maritime countries, and the results obtained therein are of enormous value to the designing of steam ships. In regard to the selection of the forms of ships naval architects are now able to proceed with practical certainty; but in connection with the design of screw propellers even after model experiments have been made with alternative forms of screws, there is still great uncertainty, and dependence upon the results obtained on "progressive" speed trials of ships is still of the greatest service. As yet the "law of comparison" between model screws and full-sized screws has not been determined accurately. The condition of the water in which screws act, as influenced by the advance of a ship and her frictional wake, the phenomena attending the passage of the water through a screw, and the impression thereon of sternward motion from which results the thrust of the propeller, the effect upon that thrust of variations in the forms and areas of the blades of screw propellers, and the causes of " cavitation," all form subjects demanding further investigation. In these cases, the only hope of finding solutions lies in the association of experimental research with mathematical analysis. There have been very many mathematical theories of the action of screw propellers, but none of these has provided the means for dealing practically with the problems of propeller design, and there is no hope that any purely mathematical investigation ever will do so, because the conditions 
which should be included in the fundamental equations are complex and to a great extent undetermined.

In connection with other branches of engineering, model experiments have also proved effective. Examples are to be found in connection with the estimates for wind pressure on complicated engineering structures-such as girder or cantilever bridges. Experimental methods are also being applied with great advantage to the study of aeronautics and the problems of flight.

The association of the mathematical analysis of past experience with designs for new engineering works of all kinds is both necessary and fruitful of benefits. A striking example of this procedure is to be found in connection with the structural arrangements of ships of unprecedented size, which have to be propelled at high speeds through the roughest seas, to carry heavy loads, to be exposed to great and rapid changes in the distribution of weight and buoyancy, and to be subjected simultaneously to rolling, pitching and heavy motions, as well as to blows of the sea. In such a case, purely mathematical investigation would be useless: the scientific interpretation of past experience and the comparison of results of calculations based on reasonable hypotheses for ships which have seen service with similar results of calculations for ships of new design are the only means which can furnish guidance.

In the past, the association of mathematicians and engineers has done much towards securing remarkable advances made in engineering practice; and in future it may be anticipated that still greater results will be attained now that the true place of mathematicians in that practice is better understood and utilized.

\section{Professor Maxime Bôcher.}

In this lecture a systematic discussion was attempted of the chief advances, both in methods and results, in the most central portions of the field in question; and in doing this it was possible at some points to unify and systematize the subject beyond the point so far secured in the literature. The lecture was confined almost entirely to linear boundary problems, that is, to the question of solving a linear differential equation subject to linear boundary conditions. 


\section{Sir Joseph Larmor.}

The essential characteristic of an electrodynamic system is the existence of the correlated fields, electric and magnetic, which occupy the space surrounding the central body, and which are an essential part of the system; to the presence of this pervading æxtherial field, intrinsic to the system, all other systems situated in that space have to adapt themselves. When a material electric system is disturbed, its electrodynamic field becomes modified, by a process which consists in propagation of change outward, after the manner of radiation, from the disturbance of electrons that is occurring in the core. The practical problems of electrodynamics are of this naturehow does the modified field of force, transmitted through the æther from a disturbed electric system, and thus established in the space around and alongside the neighboring conductors which alone are amenable to our observation, penetrate into these conductors and thereby set up electric disturbance in them also? and how does the field emitted in turn by these new disturbances interact with the original exciting field and with its core?

The idea-introduced by Faraday, developed into precision by Maxwell, expounded and illustrated in various ways by Heaviside, Poynting, Hertz- of radiant fields of force, in which all the material electric circuits are immersed, and by which all currents and electric distributions are dominated, is the root of the modern exact analysis of all electric activity.

From these postulates it is possible to understand the guidance of electric radiation by wires, the general theory of pressure exerted by waves, and to arrive at the conclusion that the pressure of radiation arises wholly from momentum carried along by the waves. The idea can be illustrated by a stretched string, but the analogy is not complete.

The next topic considered was that of momentum in æthereal fields, followed by a discussion of frictional resistance to the motion of a radiating body.

Cambridge, Eng.,

VIRGIL SNYDER. September, 1912. 